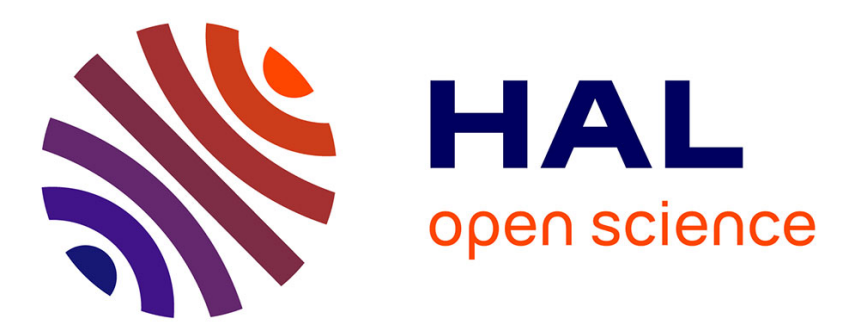

\title{
Phosphorylation-acetylation switch in the regulation of STAT1 signaling
}

Oliver H. Krämer, Thorsten Heinzel

\section{To cite this version:}

Oliver H. Krämer, Thorsten Heinzel. Phosphorylation-acetylation switch in the regulation of STAT1 signaling. Molecular and Cellular Endocrinology, 2009, 315 (1-2), pp.40. 10.1016/j.mce.2009.10.007 . hal-00547660

\section{HAL Id: hal-00547660 \\ https://hal.science/hal-00547660}

Submitted on 17 Dec 2010

HAL is a multi-disciplinary open access archive for the deposit and dissemination of scientific research documents, whether they are published or not. The documents may come from teaching and research institutions in France or abroad, or from public or private research centers.
L'archive ouverte pluridisciplinaire $\mathbf{H A L}$, est destinée au dépôt et à la diffusion de documents scientifiques de niveau recherche, publiés ou non, émanant des établissements d'enseignement et de recherche français ou étrangers, des laboratoires publics ou privés. 


\section{Accepted Manuscript}

Title: Phosphorylation-acetylation switch in the regulation of STAT1 signaling

Authors: Oliver H. Krämer, Thorsten Heinzel

PII: $\quad$ S0303-7207(09)00551-6

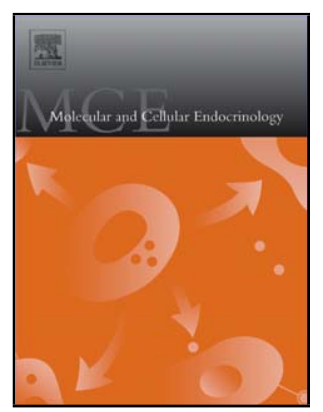

DOI: doi:10.1016/j.mce.2009.10.007

Reference: MCE 7353

To appear in: Molecular and Cellular Endocrinology

Received date:

10-6-2009

Revised date:

13-10-2009

Accepted date:

19-10-2009

Please cite this article as: Krämer, O.H., Phosphorylation-acetylation switch in the regulation of STAT1 signaling, Molecular and Cellular Endocrinology (2008), doi:10.1016/j.mce.2009.10.007

This is a PDF file of an unedited manuscript that has been accepted for publication. As a service to our customers we are providing this early version of the manuscript. The manuscript will undergo copyediting, typesetting, and review of the resulting proof before it is published in its final form. Please note that during the production process errors may be discovered which could affect the content, and all legal disclaimers that apply to the journal pertain. 


\title{
Phosphorylation-acetylation switch in the regulation of STAT1 signaling
}

Oliver H. Krämer and Thorsten Heinzel

Institute of Biochemistry and Biophysics

Center for Molecular Biomedicine (CMB)

University of Jena

Hans-Knöll-Str. 2

07743 Jena, Germany

Oliver.Kraemer@uni-jena.de

T.Heinzel@uni-jena.de

Key words: STAT1, STAT2, STAT3, acetylation, phosphorylation, histone deacetylase, interferon, TCP45

\begin{abstract}
STAT1 signaling regulates the expression of important genes controlling cell growth, differentiation, apoptosis, and immune functions. Biochemical and genetic experiments have identified how this cascade is modulated. Phosphorylation of STAT1 tyrosine and serine moieties is induced rapidly by cytokines and growth factors. Upon nuclear translocation, phosphorylated STAT1 homo- and heterodimers activate gene expression. Inactivation of phosphorylated nuclear STAT1 has to be precisely regulated in order to allow signal transduction within limited time frames. Lysine acetylation has recently been appreciated as a novel mechanism regulating signal transduction events relying on STAT proteins. Here, we review these analyses and the finding that a switch from phosphorylated to acetylated STAT1 regulates acetylation-dependent dephosphorylation of STAT1 via the T cell tyrosine phosphatase. We discuss how these observations can be integrated into our current understanding of STAT-dependent cytokine signaling and its potential relevance for endocrine functions.
\end{abstract}




\section{Regulation of STAT1 signaling}

Physiologically relevant messengers activate the signal transducers and activators of transcription (STATs). Cytokines such as interferons (IFNs) activate the transcription factor STAT1 [1-3]. They rapidly evoke the dimerization of their cognate cell surface receptors, which allows phosphorylation of receptor-associated Janus kinases (JAKs) and tyrosine kinases (TYKs) [4-6]. These enzymes catalyze the phosphorylation of carboxy-terminal tyrosine residues of STAT proteins, which is indispensable for subsequent signaling events [7]. The type I interferons IFN $\alpha$ and IFN $\beta$ stimulate phosphorylation of STAT1, STAT2, and STAT3, whereas the type II interferon IFN $\gamma$ selectively evokes phosphorylation of STAT1 $[8,9]$. Whereas type I IFNs are secreted by several cell types, activated T lymphocytes and natural killer cells selectively produce IFN $\gamma$ [10]. IFN-induced serine phosphorylation follows STAT1 tyrosine phosphorylation and modulates STAT1 signaling [11,12,13 Wojciak, 2009 \#5522] (Figure 1).

IFNs are not the only inducers of STAT1 signaling. Via Src kinase activation, the epidermal growth factor (EGF) is able to induce STAT1 tyrosine phosphorylation in cells overexpressing the EGF receptor (EGFR). Interestingly, STAT1 induction by the EGFR-SRC axis is linked to induction of the STAT1 target gene IRF1, growth arrest, and apoptosis $[14,15]$. The gonadal hormone estrogen also activates STAT1 phosphorylation and target gene activation rapidly, dependent on Src kinase and independent of classical estrogen receptor signaling [16]. Growth hormone $(\mathrm{GH})$ activates STAT1 signaling via JAK2. Of note, insulin attenuates GHreceptor expression, which indicates alteration of GH-mediated STAT1 signaling in Type 2 diabetes mellitus $[17,18]$. These results demonstrate that besides cytokines, also hormones secreted from endocrine glands can affect STAT1 signaling. This responsiveness of STAT1 towards a plethora of different signals could be the reason why STAT1 phosphorylation occurs independently of cytokines- in certain cells $[19,20]$.

Phosphorylated STAT1 forms high-affinity homodimeric and heterodimeric complexes via reciprocal interactions between the phospho-tyrosine residues (pY) and the Src homology 2 (SH2) domains [21] and (Figure 2). Whereas STAT1 tyrosine phosphorylation is only induced upon cytokine stimulation, STAT1 dimerizes with other STAT1, STAT2, and STAT3 molecules in unstimulated cells [22-27].

Phosphorylated STAT1 complexes translocate to the nucleus, where they specifically bind to promoters of IFN-stimulated genes (ISGs), which are the mediators of IFN responses $[8,28$ 30]. Curiously, activated IFN $\gamma$ and its receptor can also be detected in the nuclear compartment [31,32]. STAT1 homodimers attach to gamma interferon activated sequences (GAS). STAT1/STAT2 heterodimers bind together with interferon regulatory factor 9 (IRF9) to interferon-stimulated response elements (ISREs). The STAT1/STAT2/IRF9 complex is also termed as IFN $\alpha / \beta$-stimulated gene factor 3 (ISGF3). Hence, the selection of IFN target 
genes and their subsequent transcriptional activation are governed by individual amino acid sequences found in proteins belonging to STAT1 complexes. In the ISGF3, STAT2 contributes to transcriptional activation whilst STAT1 and IRF9 allow target gene selection [8,28-30].

Remarkably, dimerization of STAT1 is not necessary for the initiation of IFN-dependent signaling $[33,34]$. Moreover, positive and negative transcriptional control can also be exerted by unphosphorylated STAT1 via mechanisms distinct from those used by phosphorylated STAT1 [35-38].

An open, transcriptionally permissive chromatin structure is often characterized by acetylated histones [39-41]. Histone acetyltransferases (HATs) and histone deacetylases (HDACs) control histone and non-histone protein functions [42-46]. Earlier results indicated that the HATs CREB-binding protein (CBP) and p300 mediate STAT1-dependent gene expression $[47,48]$. The adenoviral early region $1 A(E 1 A)$ protein sequesters $C B P / p 300$ and this was judged as a viral mechanism for escaping IFN-stimulated immunity. However, mutant E1A which is unable to bind these HATs, blocks STAT1 [49]. Recent data demonstrate that the HATs GCN5 and p/CAF are required for IFN-dependent activation of STAT1 target genes $[40,50]$.

Since phosphorylated STAT1 binds to the HAT CBP, it is noteworthy that formation of the CBP-STAT1-complex and histone acetylation at ISGs is temporally separated [51,52]. Interestingly, STAT1-CBP complex formation even correlates with reduced histone acetylation [53,54] and a STAT1 CBP binding mutant can also support ISG expression [52]. Furthermore, acetylation events catalyzed by CBP can destabilize the enhanceosome, whereas acetylation by PCAF and GCN5 promotes enhanceosome stability via counteracting CBP-mediated acetylation [55].

Being a paradigm for ligand-induced signaling from the cell surface to the nucleus, intense efforts have been made to characterize the termination of the cytokine signal. Proteins involved in this regulatory process are IFN receptors, kinases, phosphatases (PTPS), suppressors of cytokine signaling (SOCS), and protein inhibitors of activated STAT (PIAS). Moreover, the sumoylation status of STAT1 determines IFN signaling [56-58]. Dephosphorylation of STAT1 by the T cell tyrosine phosphatase TCP45 is followed by nuclear export and latency of STAT1 $[59,60]$. A radical transition from parallel to antiparallel conformation, which allows the presentation of the phosphorylated tyrosine residues of STAT1 dimers to TCP45, has been suggested [34,61]. The existence of multiple layers of temporal and spatial regulation of cytokine-induced signaling allows precise control of genes important for metazoan growth, immune defense and development via STAT1. Recent data demonstrate that acetylation of STAT1 significantly regulates its functions (Figure 3). These findings are discussed below. 


\section{HDAC activity is required for STAT1-dependent gene expression}

HDAC activity is usually associated with transcriptional repression. However, the exclusively nuclear HDAC1 was found to be necessary for IFN-stimulated gene expression allowing innate antiviral defense [53]. This unanticipated result was obtained with the use of structurally divergent histone deacetylase inhibitors (HDACls), overexpression studies, small interfering RNA (siRNA) approaches targeted towards HDAC1, reporter gene assays, analyses of endogenous genes, and viral infection assays. In cells simultaneously treated with the HDACi trichostatin A (TSA) and IFN, the HDACi did not affect the phosphorylation, dimerization, nuclear translocation, and DNA binding activity of activated STAT1. Hence, the repression of STAT1 signaling due to HDAC inhibition is unlikely to involve an attenuation of kinases. Short term incubations with IFN also did not alter the interactions of STAT1 and STAT2 with HDAC1, HDAC4, and HDAC5. Nevertheless, TSA counteracted deacetylation of histone $\mathrm{H} 4$ at the ISG54 ISRE in response to IFN $\alpha$. This finding indicates that chronically sustained histone acetylation interferes with the IFN signal. Nusinzon and Horvath furthermore observed that STAT3 signaling can be inhibited by TSA, which indicates that acetylation not only impairs STAT1.

The HDACi butyrate can ameliorate aberrant inflammatory processes. Interestingly, pretreatment of cells with this substance prevented phosphorylation, nuclear translocation, DNA binding, and GAS-dependent transcription in response to IFN $\gamma$, and inhibition of JAK2 by butyrate correlates with the lack of STAT1 signaling. [62]. Instead of co-incubating cells with HDACi and IFN, pre-incubation of cells with the HDACi allowed this slower acting compound [63] to antagonize the rapidly acting IFNs.

Virally mediated IFN-induced translocation of STAT2 and formation of a DNA-binding ISGF3 are also inhibited by the HDACi TSA, when added before stimulation with IFN [64]. IFNstimulated transcription of several ISGF3-dependent ISGs, e.g. of IRF7, was accordingly prevented in virus-infected TSA-treated cells. ISGF3-independent transcription of IRF3 though was not affected by TSA indicating that HDACs are required only for STAT1/STAT2dependent gene expression. These data suggest that these proteins serve as substrates for nuclear acetylation attenuating ISGF3 complex formation and transcriptional activation.

Shortly after these publications, three additional reports confirmed that HDACs are required for STAT1 signaling $[29,65,66]$. The structurally unrelated HDACls butyrate, TSA, and suberoylanilide hydroxamic acid (SAHA) inhibit IFN $\gamma$-induced tyrosine phosphorylation and nuclear translocation of STAT1 [66]. Overexpression and siRNA analyses revealed that the class I HDACs HDAC1, HDAC2, and HDAC3 are critically required for STAT1-dependent transcriptional activation by IFN $\gamma$. This study furthermore shows that HDACIs reduced JAK1 
activation, which might cause impaired STAT1 phosphorylation, nuclear translocation, and expression of the ISG interferon regulatory factor 1 (IRF1).

Nevertheless, this report demonstrates that HDACls and IFN $\gamma$ cooperatively induce apoptosis of colon cancer cells. We and others similarly demonstrated that IFN $\alpha$ and HDACls synergistically evoke apoptotic cell death of STAT1 positive melanoma cells [35]. Such observations can be explained by effects beyond STAT1 signaling. For example, both substances inhibit anti-apoptotic nuclear factor kappa B (NF-kB) target genes $[35,66]$. In addition, STAT1 is not required for IFN $\gamma$-induced expression of the apoptosis inducer Caspase 7, and such STAT1-independent signaling is not subject to inhibition by HDACls [66].

Analyzing a large set of endogenous BRG1-dependent and-independent ISGs, it was found that the HDACls TSA, valproic acid (VPA), and HC toxin globally blocked the induction of STAT1/STAT2 target genes and antiviral responses [29]. Basal expression of the genes analyzed was nonetheless not influenced by HDACls, and IFN did not inhibit gene expression induced by these agents. Tyrosine phosphorylation, nuclear translocation, and DNA-binding of STAT1 were not altered by HDACls. HDAC function was however required in a GCN5-dependent heterologous assay with the STAT2 transcriptional activation domain (TAD). Furthermore, HDACs are necessary for virally induced gene expression via the IFN regulatory factor 3 (IRF3) cooperating with p300. Since these authors could not detect acetylation of STAT2, it appears that that HDACs are required for rapid IFN-stimulated ISG expression independent of STAT2 acetylation.

HDACls have furthermore been reported to inhibit the recruitment of RNA polymerase II via IRF9 to ISRE-containing ISGs [65]. Although this effect was antagonized by overexpressed IRF9, acetylation of IRF9 could not be detected and the STAT1/STAT2 binding interface of IRF9 was not required to rescue the effects of TSA on IFN signaling. Thus, the attraction of RNA polymerase II to IFN-stimulated genes requires HDAC activity and IRF9 independent of the IRF9 acetylation status.

Similar to the above mentioned studies, induction of the promyelocytic leukemia protein (PML), SP100, and IRF1 by IFN $\alpha$ are prevented by different HDACIs (TSA, sodium butyrate, MS-27-275, SAHA, and VPA) [67]. This report additionally shows that HDACls do not disturb the IFN-induced nuclear transport of phosphorylated STAT2 and its binding to the ISRE in the PML promoter. Therefore, HDACls cause a defect in IFN signaling within the nucleus and HDAC activity is necessary for full transcriptional activation of ISGs.

The analysis of HDAC1 knock out MEFs added further proof to the finding that HDAC activity is required for IFN-dependent gene expression. This study demonstrated that albeit the majority of HDAC1 target genes are repressed by this enzyme, IFN-regulated genes (irf1 and gbp2) are positively regulated by HDAC1 [54]. This novel function of HDAC1 as a 
transcriptional coactivator is in agreement with the many analyses performed with HDACls. Hence, HDAC1 appears to control IFN signaling via deacetylation of a nuclear substrate.

Taken together these studies clearly show that HDAC activity is required for STAT1dependent gene expression. Hence these enzymes are required for the initiation of STAT1 signaling in the cytoplasm and in the nucleus.

\section{IFN-dependent STAT1 signaling is terminated via acetylation of STAT1}

Acetylation is appreciated as a functionally important protein modification [42,44,46]. Mutant molecules mimicking acetylation or being non-acetylatable have yielded valuable insights into the physiological roles of acetylation (Figure 2).

Considering that acetylation counteracts IFN signaling, it was speculated that HDACs and HDACls affect STAT1 activity directly by acetylation. We revealed that HDACls and IFNs promote acetylation of STAT1 by CBP in tumor cells of various origins [35]. This observation is consistent with dynamic interactions of STAT1 with HATs and HDACs. Our observations have been confirmed in other systems, including an in vivo mouse model of pancreatitis $[23,58,68,69]$. Of note, excessive immune stimulation is linked to pancreatic tumorigenesis [70,71]. Acetylated STAT1 might therefore counteract tumorigenesis, which could explain why tumors from various entities frequently express STAT1 at decreased levels compared to normal tissue $[72,73]$. It is however difficult to judge precisely which pro-inflammatory effects of STAT1 and other modulators of immune cells affect tumor growth and development [74]. Surely, a delicate balance of immunological functions is crucial for health and disease.

In unstimulated cells, low levels of acetylated STAT1 are present and HDACls evoke STAT1 acetylation more slowly than IFNs. This finding can be easily explained by the very low levels of STAT1 residing in the nucleus, near its HAT CBP. Furthermore, IFNs cause nuclear translocation of STAT1, whereas HDACls do not alter the cytoplasmic localization of STAT1 $[29,35,53,65,66]$ and (Figure 4). We could additionally specify that STAT1 is acetylated by $\mathrm{CBP}$ at the $\varepsilon$-amino groups of the lysine residues $\mathrm{K} 410$ and $\mathrm{K} 413$. Of note, K410 and K413 contribute to the surface-exposed DNA-binding domain (DBD) common to all STATs. This localization allows accessibility of modifying enzymes and interactions with proteins [35].

We further analyzed STAT1 signaling in vitro and in cells with IFN, HDACls, PTP inhibition, ectopic expression, RNA interference, and several STAT1 acetylation site mutants. Our analyses reveal a functional phosphorylation-acetylation switch. Rapid IFN-induced activation and nuclear translocation of STAT1 allows its acetylation by CBP. Subsequently, the association of acetylated STAT1 with the highly active tyrosine phosphatase TCP45 terminates signaling. This enzyme can thus be judged as a transmission control protein dominantly restricting IFN signaling. In addition, STAT1 is the first signaling molecule 
identified to be cross-modulated by IFN-induced tyrosine phosphorylation and lysine acetylation [75].

Apart from allowing TCP45 binding, K410 and K413 contact the DNA backbone. Acetylation of these residues may therefore weaken this interaction and facilitate presentation of the $p Y$ residue to TCP45 $[25,33,34]$. Such a switch from active tyrosine phosphorylated STAT1 to suppressed lysine acetylated STAT1 generates two different functional modes of STAT1. Via this mechanism, STAT1 target genes can be induced rapidly and the cytokine signal can be terminated afterwards by CBP-mediated STAT1 acetylation.

Removal of IFN allows disruption of the STAT1-CBP-TCP45 complex and the re-association of HDAC3 with STAT1. Deacetylation of STAT1 by HDAC3, which is located in the cytoplasm as well as in the nucleus, thus allows re-stimulation of STAT1 [75]. In agreement with this finding, attenuation of HDAC3 causes STAT1 acetylation and impaired IFN signaling. Of note, HDAC3 similarly closes an acetylation-dependent cycle of the cytokine-inducible STAT3 and NF-kB transcription factors, whereas nuclear HDAC1 most likely contributes to IFN-induced transcriptional activation by STAT1 $[53,54,66]$.

These data demonstrate that acetylation counteracts IFN-dependent signaling via STAT1, although histone acetylation usually promotes transcription. In line with these observations, acetylation-deficient STAT1 K410R,K413R activates ISGs even more potently in the presence of HDACls, and independent of whether or not cells had been pre-incubated or treated with such substances at the time of the IFN pulse. Hence, site- and substrate-specific acetylation events are important for IFN-induced transcription via phosphorylated STAT1 [75] and (Table 1).

\section{Diverse posttranslational modifications of STAT1}

Phosphorylation and acetylation are not the only posttranslational modifications of STAT1. Whereas there is debate on whether STAT1 undergoes lysine methylation [76-78], modification of K703 with the small Ubiquitin-like modifier SUMO1 was frequently observed in IFN-treated cells [79-82]. Similar to acetylation, sumoylation of STAT1 antagonizes its phosphorylation at Y701 and subsequent signaling (Figure 4). Mechanistically, this could be due to sterical hindrance of kinases due to the bulky SUMO adduct [83,84]. STAT1 S727 phosphorylation occurs on chromatin-bound STAT1 and facilitates inhibitory modification of STAT1 with SUMO1 [13]. Thus, a tyrosine phosphorylation-acetylation-switch and a serine phosphorylation-sumoylation switch regulate STAT1 signaling.

Ubiquitin and ISG15 can also be conjugated to STAT1 lysine residues. However, ISGylation of STAT1 does not appear to be crucial for its signaling [85-87]. Ubiquitinylation of STAT1 [88] was reported to be mediated by the E3 ligases C-CBL (Casitas B-lineage lymphoma) [89] or SLIM (STAT-interacting LIM protein) [90]. SLIM acts in concert with PKR (RNA-dependent 
protein kinase) [91,92] and this E3 is also critical for STAT1 degradation in mammary epithelial tumor cells exposed to the secreted glycoprotein Osteopontin [93]. Since STAT1 promotes its own synthesis strongly after its induction via IFNs [38,75,94,95], stimulusinduced degradation of this protein is hardly or not at all detectable.

How do posttranslational modifications affect each other - positively or negatively, synergistically or additively, dynamically or not at all? When asking such questions it should be kept in mind that at a given time point the individual rates of posttranslational modifications might be very low, but still very relevant. Such observations have already been taken into account for sumoylation [96,97]. For example, the inhibitory role of STAT1 sumoylation could only be detected upon forced modification of STAT1 with SUMO1 [83,84]., Equally, cytokines evoke tyrosine phosphorylation and nuclear translocation of only a portion of the cellular STAT1 pool [10]. Accordingly, acetylation of a single molecule could impose latency on STAT1 oligomers via recruitment of the highly active TCP45. Furthermore, in a heterodimeric STAT1/STAT3 complex $[24,26]$, recruitment of TCP45 via acetylated STAT1 might inactivate STAT3. Since STAT3 contributes to the development of tumors of the endocrine system [74] HDACls could attenuate such processes via STAT1 acetylation.

High sensitivity of cells towards rather low amounts of modified modulators ensures efficiency and allows rapid adaptation, fine-tuned responses over time, variations in signal strength, and the possibility for re-stimulating the remaining, naïve pool of signaling molecules [75].

\section{Regulation of other STAT proteins via acetylation}

Concerning the acetylation of other STAT family members, a number of reports have been published. The first STAT protein shown to undergo acetylation has been STAT6 [98]. This study showed that transcription of reticulocyte-type 15-lipoxygenase-1 is enhanced in HDACi-treated cells. In contrast, STAT5-dependent gene expression induced by interleukin 3 is counteracted by TSA [99]. Acetylation of STAT2 and STAT3 has recently been characterized in detail.

\subsection{Acetylation of STAT2}

It was recently reported that IFN $\alpha$ provokes immediate recruitment of nuclear CBP to extracellular membrane-bound IFNAR molecules, and that CBP-mediated acetylation of IFNAR2 on K399 and STAT2 on K390 enables the binding of IRF9 [23]. In the absence of physiological stimulation with IFN $\alpha$, antiviral gene expression and activity are enhanced when all these components and CBP are overexpressed. Such significant roles for CBPmediated acetylation of IFNAR, STAT1, STAT2, and IRF9 in IFN signaling argue for acetylation as a positive regulator of STAT1 signaling. Nevertheless, Tang et al. also revealed that whereas wild-type MEFs could not induce STAT1/STAT2 target genes in 
response to IFN $\alpha$, CBP knock out MEFs induced ISG15. Intriguingly, this study presents HDAC6 as the deacetylase counteracting IFN signaling. This HDAC is inhibited by the hydroxamic acids TSA and SAHA, but not by HDACls used in other studies assessing the impact of acetylation on the IFN signal. Nevertheless, HDACls have been proven to suppress IFN-mediated STAT1 signaling [29,53,54,62,65-67,75]. It therefore appears that further studies are required to illustrate how such acetylation events might be integrated into the established negative role of acetylation on STAT1/STAT2 signaling (Table 1).

\subsection{C-terminal acetylation of STAT3}

Several studies analyzed the cytokine-dependent acetylation of STAT3 [100-104]. Two reports stated that $\mathrm{K} 685$, located within the exterior surface of the STAT3 SH2 domain, is the primary STAT3 moiety acetylated by CBP or p300 in response to treatment with cytokines and HDACls [101,102] and (Figure 2). A K685R STAT3 mutant revealed that lysine K685 is critical for the formation of stable STAT3 dimers, DNA binding, and transcriptional regulation [102]. It would be interesting to see how a STAT3 K685Q mutant mimicking acetylation at this site behaves, and how positive regulation of the oncogene STAT3 via HDACls is compatible with the growth inhibitory and pro-apoptotic actions of such drugs [42,44-46,105].

\section{$5.3 \mathrm{~N}$-terminal acetylation of STAT3}

Two other lysines, K49 and K87, located in the STAT3 NH2-terminus, are acetylated by p300 in cultured cells and in mice [103]. Acetylation of these sites positively regulates interactions of STAT3 with p300 and enhanceosome assembly [104]. On the other hand, STAT3 activation by interleukin 6 requires balanced HDAC1 levels ensuring appropriate nucleocytoplasmic distribution of STAT3 [100]. These reports substantiate that acetylation crucially contributes to STAT signaling at different levels and via various mechanisms.

\section{Concluding remarks}

Equal to phosphorylation, acetylation of signaling molecules can promote or inhibit signaling, gene expression, and the formation of protein complexes [106,107]. Being a paradigm for a pathway requiring deacetylase activity, the molecular mechanisms regulating STAT1 acetylation have been analyzed intensively. Acetylation of STAT1 depends on the balance between its associated HDACs and the HAT CBP [35] and (Figure 5). HDACls as well as IFNs enhance the expression of STAT proteins and IRF9 $[29,35,108]$. Nevertheless, these agents also induce STAT1 acetylation and experimental data agree that acetylation counteracts ISG expression (Table 1). In line with these facts, CBP-mediated acetylation of STAT1 antagonizes and HDACs are required for IFN-dependent signaling [75]. Additional mechanisms might contribute to and ensure acetylation-dependent latency of STAT1. For example, the reduced interaction of acetylated STAT1 with HDACs and cytosolic translocation of CBP, which possibly recognizes acetyl-STAT1 via its bromodomain, could 
maintain STAT1 acetylation. In addition, the formation of STAT1 multimers harboring TCP45 could affect the STAT1 pool independent of whether or not an individual molecule had been previously activated or not $[33,75,107,109]$.

Does a phosphorylation-acetylation switch antagonistically regulate each STAT family member? Although they all interact with HATs and HDACs, assessing the specific consequences of their acetylation requires individual analyses. For example, STAT1 acetylation does not affect STAT2, which is not inactivated by TCP45 and which, in contrast to STAT1, prefers binding of p300 over CBP $[60,67,75,110]$. Furthermore, STAT1 and STAT3 are very similar in structure, though close inspection reveals that K410 and K413 correspond to arginines in STAT3. Hence, a putative negative regulation of STAT3 by acetylation of these moieties is not feasible. Since STATs 4,5 , and 6 harbor lysine residues at the corresponding positions [111], these proteins might be regulated via acetylation similar to STAT1. Such regulatory effects could be linked to signal longevity, which determines STAT5-dependent mammary functions induced by prolactin and laminin and likely also cancer-relevant processes $[112,113]$. On the other hand, the lysine residue corresponding to K685 in STAT3, K679 in STAT1, is unlikely to participate in acetylation-dependent repression of STAT1 signaling [75] and (Figure 6). Hence, individual amino acid residues very specifically regulate phosphorylation-acetylation switches regulating STAT protein functions.

The novel findings discussed here stress that simple models positioning HDACs as transcriptional repressors and HATs as transcriptional activators do not universally hold true. Studying IFN-induced STAT1-dependent signaling has instead broadened our view on how acetylation can counteract cytoplasmic and nuclear signaling events. Growth factors and hormones can also induce signaling via STAT1 [1-3,19,32]. Further studies will reveal whether signals beyond IFNs similarly attenuate STAT1 signaling via acetylation.

Translatorial research has demonstrated that HDACi ameliorate unbalanced immunological functions. STAT1 acetylation impairs STAT1 itself as well as NF-kB $[35,68,75]$. These proteins are key mediators of the inflammatory response and a multitude of factors regulate this process. The sex steroid hormone estrogen can for example suppress NF- $\kappa B$-dependent IL-6 production in liver-associated macrophages (Kupffer cells), which may explain sexdependent differences in cancer susceptibilities at various sites [114]. Inflammation is associated with certain cancers of endocrine tissues, e.g. with thyroid and pancreatic cancers $[70,71,115]$. Interestingly, STAT1 expression can be down-regulated in pancreatic cancers, head and neck tumors, and melanomas [35,72,73] and IFN $\gamma$ induces acetylation of STAT1 counteracting pancreatitis [68]. HDACi-induced STAT1 expression and acetylation might thus contribute to the correction of chronic inflammatory processes contributing to cancer development [116-118]. 
Analyses of STAT1 acetylation have broadened our understanding of cytokine signaling and subsequent gene regulation. Increasing evidence accumulates that the view on transcriptionally repressive HDACs and activating HATs appears too narrow $[42,75,105]$. Of note, cyclic recruitment of HDACs, HATs, and other transcriptional regulators is a pivotal feature of estrogen-dependent gene expression within the context of an endogenous promoter [119]. In light of these facts, dynamic models appear to supersede static views on signaling processes and epigenetic regulators. 
Table1: Reported effects of acetylation on IFN-induced STAT1 signaling

\begin{tabular}{|c|c|c|}
\hline $\begin{array}{c}\text { Stimuli } \\
\text { (IFN / HDACls) }\end{array}$ & $\begin{array}{c}\text { Effect of acetylation events on } \\
\text { STAT1 signaling }\end{array}$ & Reference \\
\hline $\begin{array}{c}\text { IFN } \alpha ; \text { IFN } \gamma / \\
\text { TSA; } \mathrm{NaB}\end{array}$ & Inhibitory & [53] \\
\hline $\begin{array}{c}\mathrm{IFN} \gamma / \\
\mathrm{NaB}\end{array}$ & Inhibitory & [62] \\
\hline $\begin{array}{l}\text { IFN } \alpha / \\
\text { TSA }\end{array}$ & Inhibitory & [64] \\
\hline $\begin{array}{c}\text { IFN } \beta / \\
\text { TSA }\end{array}$ & Inhibitory & [60] \\
\hline $\begin{array}{l}\text { IFN } \alpha ; \text { IFN } \gamma / \\
\text { TSA; VPA; HC }\end{array}$ & Inhibitory & [29] \\
\hline $\begin{array}{c}\mathrm{IFN} \gamma / \\
\text { TSA; NaB; SAHA }\end{array}$ & Inhibitory & [66] \\
\hline $\begin{array}{c}\mathrm{IFN} \gamma / \\
\mathrm{TSA}\end{array}$ & Inhibitory & [54] \\
\hline $\begin{array}{c}\text { IFN } \alpha / \\
\text { TSA; VPA; NaB; } \\
\text { MS; SAHA }\end{array}$ & Inhibitory & [67] \\
\hline $\begin{array}{l}\text { IFN } \alpha \text { / } \\
\text { TSA }\end{array}$ & Activating & [23] \\
\hline $\begin{array}{c}\text { IFN } \alpha / \\
\text { TSA; VPA; NaB }\end{array}$ & Inhibitory & [75] \\
\hline
\end{tabular}

IFN, interferon; TSA, trichostatin A; NaB, sodium butyrate; VPA, valproic acid; HC, HC toxin; MS, MS-27-275; SAHA, suberoylanilide hydroxamic acid 


\section{Figure 1: Activation of STAT1 by diverse signaling pathways}

Cytokines, growth factors, and hormones induce phosphorylation of STAT1, which is catalyzed by receptor-associated kinases in the cytosol. Phosphorylated STAT1 homo- or heterodimers translocate to the nucleus and evoke STAT1-dependent gene expression. See text for abbreviations.

\section{Figure 2: Structures of STAT1 and STAT3}

Domains and phosphorylation and acetylation sites of STAT1 and STAT3: NTD, N-terminal domain; CC, coiled coil; DBD, DNA-binding domain; LD, linker domain; SH2, Src-homology domain 2; TAD, transcriptional activation domain; $\mathrm{p}$, phosphorylation; ac, acetylation; $\mathrm{K}$, lysine. The properties of acetylated or non-acetylated lysine residues can be emulated by mutations. Glutamine $(Q)$ mimics acetylated lysine $(K)$, whereas arginine $(R)$ retains the positive charge, but cannot be acetylated due to the mesomerically stabilized guanidino group.

\section{Figure 3: Termination of STAT1 signaling via acetylation}

IFNs induce STAT1 signaling. The nuclear HAT CBP catalyzes acetylation of phosphorylated nuclear STAT1. Subsequently, TCP45 is recruited and STAT1 becomes dephosphorylated, exits the nucleus, and acquires latency. See text for abbreviations.

Figure 4: A phospho-acetyl switch controls STAT1 signaling

Modifications of STAT1 are dynamically regulated. A phospho-acetyl switch controls STAT1 upon activation by IFN. Serine phosphorylation of STAT1 regulates repressive sumoylation of STAT1 (pY, tyrosine phosphorylation; Ac, lysine acetylation; pS, serine phosphorylation; Su, sumoylation; MAPK, MAP kinases). STAT1/STAT2 heterodimers serve as example. See text for all further abbreviations.

\section{Figure 5: Acetylation of STAT1 antagonizes its IFN-induced phosphorylation}

The balance between STAT1 acetylation and phosphorylation determines STAT1 activity and IFN signaling. STAT1 homodimers serve as an example. See text for abbreviations.

\section{Figure 6: Acetylation sites of the structurally related proteins STAT1 and STAT3}

Functionally relevant acetylation sites of STAT1 and STAT3: The critical STAT1 lysine moieties $\mathrm{K} 410$ and $\mathrm{K} 413$ are arginines in STAT3 and therefore cannot be subject to acetylation. Likewise, the N-terminal lysine K49 of STAT3 does not correspond to a lysine in STAT1. The STAT3 acetylation site K685 corresponds to STAT1 K679. 


\section{References}

[1] Stark, G.R. (2007) How cells respond to interferons revisited: from early history to current complexity. Cytokine Growth Factor Rev 18, 419-23.

[2] Darnell, J.E., Jr. (2007) Interferon research: impact on understanding transcriptional control. Curr Top Microbiol Immunol 316, 155-63.

[3] Schindler, C., Levy, D.E. and Decker, T. (2007) JAK-STAT signaling: from interferons to cytokines. J Biol Chem 282, 20059-63.

[4] Ihle, J.N. (2001) The Stat family in cytokine signaling. Curr Opin Cell Biol 13, 211-7.

[5] Haan, C., Kreis, S., Margue, C. and Behrmann, I. (2006) Jaks and cytokine receptors-an intimate relationship. Biochem Pharmacol 72, 1538-46.

[6] Schindler, C. and Plumlee, C. (2008) Inteferons pen the JAK-STAT pathway. Semin Cell Dev Biol 19,311-8.

[7] Reich, N.C. (2007) STAT dynamics. Cytokine Growth Factor Rev 18, 511-8.

[8] Platanias, L.C. (2005) Mechanisms of type-I- and type-II-interferon-mediated signalling. Nat Rev Immunol 5, 375-86.

[9] Klein, B., Tarte, K., Jourdan, M., Mathouk, K., Moreaux, J., Jourdan, E., Legouffe, E., De Vos, J. and Rossi, J.F. (2003) Survival and proliferation factors of normal and malignant plasma cells. Int J Hematol 78, 106-13.

[10] Meyer, T., Gavenis, K. and Vinkemeier, U. (2002) Cell type-specific and tyrosine phosphorylation-independent nuclear presence of STAT1 and STAT3. Exp Cell Res 272, 45-55.

[11] Varinou, L., Ramsauer, K., Karaghiosoff, M., Kolbe, T., Pfeffer, K., Muller, M. and Decker, T. (2003) Phosphorylation of the Stat1 transactivation domain is required for full-fledged IFN-gamma-dependent innate immunity. Immunity 19, 793-802.

[12] Sadzak, I., Schiff, M., Gattermeier, I., Glinitzer, R., Sauer, I., Saalmüller, A., Yang, E., Schaljo, B. and Kovarik, P. (2008) Recruitment of Stat1 to chromatin is required for interferon-induced serine phosphorylation of Stat1 transactivation domain. Proc Natl Acad Sci U S A 105, 8944-9.

[13] Vanhatupa, S., Ungureanu, D., Paakkunainen, M. and Silvennoinen, O. (2008) MAPK-induced Ser727 phosphorylation promotes SUMOylation of STAT1. Biochem J 409, 179-85.

[14] Andersen, P., Pedersen, M.W., Woetmann, A., Villingshoj, M., Stockhausen, M.T., Odum, N. and Poulsen, H.S. (2008) EGFR induces expression of IRF-1 via STAT1 and STAT3 activation leading to growth arrest of human cancer cells. Int J Cancer 122, 342-9.

[15] Grudinkin, P.S., Zenin, V.V., Kropotov, A.V., Dorosh, V.N. and Nikolsky, N.N. (2007) EGF-induced apoptosis in A431 cells is dependent on STAT1, but not on STAT3. Eur J Cell Biol 86, 591-603.

[16] Kennedy, A.M., Shogren, K.L., Zhang, M., Turner, R.T., Spelsberg, T.C. and Maran, A. (2005) 17beta-estradiol-dependent activation of signal transducer and activator of transcription-1 in human fetal osteoblasts is dependent on Src kinase activity. Endocrinology 146, 201-7.

[17] Xu, J., Ji, S., Venable, D.Y., Franklin, J.L. and Messina, J.L. (2005) Prolonged insulin treatment inhibits GH signaling via STAT3 and STAT1. J Endocrinol 184, 481-92.

[18] Xu, J., Liu, Z., Clemens, T.L. and Messina, J.L. (2006) Insulin reverses growth hormone-induced homologous desensitization. J Biol Chem 281, 21594-606.

[19] Subramaniam, P.S., Torres, B.A. and Johnson, H.M. (2001) So many ligands, so few transcription factors: a new paradigm for signaling through the STAT transcription factors. Cytokine 15, 175-87. 
[20] Liddle, F.J., Alvarez, J.V., Poli, V. and Frank, D.A. (2006) Tyrosine phosphorylation is required for functional activation of disulfide-containing constitutively active STAT mutants. Biochemistry 45, 5599-605.

[21] Brierley, M.M. and Fish, E.N. (2005) Stats: multifaceted regulators of transcription. J Interferon Cytokine Res 25, 733-44.

[22] Braunstein, J., Brutsaert, S., Olson, R. and Schindler, C. (2003) STATs dimerize in the absence of phosphorylation. J Biol Chem 278, 34133-40.

[23] Tang, X., Gao, J.S., Guan, Y.J., McLane, K.E., Yuan, Z.L., Ramratnam, B. and Chin, Y.E. (2007) Acetylation-dependent signal transduction for type I interferon receptor. Cell 131, 93-105.

[24] Gupta, S., Yan, H., Wong, L.H., Ralph, S., Krolewski, J. and Schindler, C. (1996) The SH2 domains of Stat1 and Stat 2 mediate multiple interactions in the transduction of IFN-alpha signals. Embo J 15, 1075-84.

[25] Mao, X., Ren, Z., Parker, G.N., Sondermann, H., Pastorello, M.A., Wang, W., McMurray, J.S., Demeler, B., Darnell, J.E., Jr. and Chen, X. (2005) Structural bases of unphosphorylated STAT1 association and receptor binding. Mol Cell 17, 761-71.

[26] Stancato, L.F., David, M., Carter-Su, C., Larner, A.C. and Pratt, W.B. (1996) Preassociation of STAT1 with STAT2 and STAT3 in separate signalling complexes prior to cytokine stimulation. J Biol Chem 271, 4134-7.

[27] Ndubuisi, M.I., Guo, G.G., Fried, V.A., Etlinger, J.D. and Sehgal, P.B. (1999) Cellular physiology of STAT3: Where's the cytoplasmic monomer? J Biol Chem 274, 25499509.

[28] Kerr, I.M., Costa-Pereira, A.P., Lillemeier, B.F. and Strobl, B. (2003) Of JAKs, STATs, blind watchmakers, jeeps and trains. FEBS Lett 546, 1-5.

[29] Chang, H.M., Paulson, M., Holko, M., Rice, C.M., Williams, B.R., Marie, I. and Levy, D.E. (2004) Induction of interferon-stimulated gene expression and antiviral responses require protein deacetylase activity. Proc Natl Acad Sci U S A 101, 9578-83.

[30] Levy, D.E. and Darnell, J.E., Jr. (2002) Stats: transcriptional control and biological impact. Nat Rev Mol Cell Biol 3, 651-62.

[31] Johnson, H.M., Subramaniam, P.S., Olsnes, S. and Jans, D.A. (2004) Trafficking and signaling pathways of nuclear localizing protein ligands and their receptors. Bioessays 26, 993-1004.

[32] Krolewski, J.J. (2005) Cytokine and growth factor receptors in the nucleus: what's up with that? J Cell Biochem 95, 478-87.

[33] Mertens, C., Zhong, M., Krishnaraj, R., Zou, W., Chen, X. and Darnell, J.E., Jr. (2006) Dephosphorylation of phosphotyrosine on STAT1 dimers requires extensive spatial reorientation of the monomers facilitated by the N-terminal domain. Genes Dev 20, 3372-81.

[34] Zhong, M., Henriksen, M.A., Takeuchi, K., Schaefer, O., Liu, B., ten Hoeve, J., Ren, Z., Mao, X., Chen, X., Shuai, K. and Darnell, J.E., Jr. (2005) Implications of an antiparallel dimeric structure of nonphosphorylated STAT1 for the activationinactivation cycle. Proc Natl Acad Sci U S A 102, 3966-71.

[35] Krämer, O.H., Baus, D., Knauer, S.K., Stein, S., Jager, E., Stauber, R.H., Grez, M., Pfitzner, E. and Heinzel, T. (2006) Acetylation of Stat1 modulates NF-kappaB activity. Genes Dev 20, 473-85.

[36] Yang, J. and Stark, G.R. (2008) Roles of unphosphorylated STATs in signaling. Cell Res 18, 443-51.

[37] Chatterjee-Kishore, M., Wright, K.L., Ting, J.P. and Stark, G.R. (2000) How Stat1 mediates constitutive gene expression: a complex of unphosphorylated Stat 1 and IRF1 supports transcription of the LMP2 gene. Embo J 19, 4111-22. 
[38] Cheon, H. and Stark, G.R. (2009) Unphosphorylated STAT1 prolongs the expression of interferon-induced immune regulatory genes. Proc Natl Acad Sci U S A 106, 9373 8.

[39] Kouzarides, T. (2007) Chromatin modifications and their function. Cell 128, 693-705.

[40] Paulson, M., Press, C., Smith, E., Tanese, N. and Levy, D.E. (2002) IFN-Stimulated transcription through a TBP-free acetyltransferase complex escapes viral shutoff. Nat Cell Biol 4, 140-7.

[41] Heinzel, T. and Krämer, O.H. (2007) Pharmacodynamic markers for histone deacetylase inhibitor development. Drug Discovery Today: Disease Mechanisms

4, 277-283.

[42] Spange, S., Wagner, T., Heinzel, T. and Krämer, O.H. (2009) Acetylation of nonhistone proteins modulates cellular signalling at multiple levels. Int J Biochem Cell Biol 41, 185-98.

[43] Brandl, A., Heinzel, T. and Krämer, O.H. (2009) Histone deacetylases: salesmen and customers in the post-translational modification market. Biol Cell 101, 193-205.

[44] Bolden, J.E., Peart, M.J. and Johnstone, R.W. (2006) Anticancer activities of histone deacetylase inhibitors. Nat Rev Drug Discov 5, 769-84.

[45] Krämer, O.H., Göttlicher, M. and Heinzel, T. (2001) Histone deacetylase as a therapeutic target. Trends in Endocrinology and Metabolism 12, 294-300.

[46] Yoo, C.B. and Jones, P.A. (2006) Epigenetic therapy of cancer: past, present and future. Nat Rev Drug Discov 5, 37-50.

[47] Bhattacharya, S., Eckner, R., Grossman, S., Oldread, E., Arany, Z., D'Andrea, A. and Livingston, D.M. (1996) Cooperation of Stat2 and p300/CBP in signalling induced by interferon-alpha. Nature 383, 344-7.

[48] Horvai, A.E., Xu, L., Korzus, E., Brard, G., Kalafus, D., Mullen, T.M., Rose, D.W., Rosenfeld, M.G. and Glass, C.K. (1997) Nuclear integration of JAK/STAT and Ras/AP-1 signaling by CBP and p300. Proc Natl Acad Sci U S A 94, 1074-9.

[49] Look, D.C., Roswit, W.T., Frick, A.G., Gris-Alevy, Y., Dickhaus, D.M., Walter, M.J. and Holtzman, M.J. (1998) Direct suppression of Stat1 function during adenoviral infection. Immunity 9, 871-80.

[50] Masumi, A., Wang, I.M., Lefebvre, B., Yang, X.J., Nakatani, Y. and Ozato, K. (1999) The histone acetylase PCAF is a phorbol-ester-inducible coactivator of the IRF family that confers enhanced interferon responsiveness. Mol Cell Biol 19, 1810-20.

[51] Christova, R., Jones, T., Wu, P.J., Bolzer, A., Costa-Pereira, A.P., Watling, D., Kerr, I.M. and Sheer, D. (2007) P-STAT1 mediates higher-order chromatin remodelling of the human MHC in response to IFNgamma. J Cell Sci 120, 3262-70.

[52] Ramsauer, K., Farlik, M., Zupkovitz, G., Seiser, C., Kroger, A., Hauser, H. and Decker, T. (2007) Distinct modes of action applied by transcription factors STAT1 and IRF1 to initiate transcription of the IFN-gamma-inducible gbp2 gene. Proc Natl Acad Sci U S A 104, 2849-54.

[53] Nusinzon, I. and Horvath, C.M. (2003) Interferon-stimulated transcription and innate antiviral immunity require deacetylase activity and histone deacetylase 1 . Proc Natl Acad Sci U S A 100, 14742-7.

[54] Zupkovitz, G., Tischler, J., Posch, M., Sadzak, I., Ramsauer, K., Egger, G., Grausenburger, R., Schweifer, N., Chiocca, S., Decker, T. and Seiser, C. (2006) Negative and positive regulation of gene expression by mouse histone deacetylase 1 . Mol Cell Biol 26, 7913-28.

[55] Munshi, N., Agalioti, T., Lomvardas, S., Merika, M., Chen, G. and Thanos, D. (2001) Coordination of a transcriptional switch by HMGI(Y) acetylation. Science 293, 11336. 
[56] Liu, B. and Shuai, K. (2008) Targeting the PIAS1 SUMO ligase pathway to control inflammation. Trends Pharmacol Sci 29, 505-9.

[57] Lim, C.P. and Cao, X. (2006) Structure, function, and regulation of STAT proteins. Mol Biosyst 2, 536-50.

[58] Kim, H.S. and Lee, M.S. (2007) STAT1 as a key modulator of cell death. Cell Signal $19,454-65$.

[59] ten Hoeve, J., de Jesus Ibarra-Sanchez, M., Fu, Y., Zhu, W., Tremblay, M., David, M. and Shuai, K. (2002) Identification of a nuclear Stat1 protein tyrosine phosphatase. Mol Cell Biol 22, 5662-8.

[60] Sakamoto, S., Qin, J., Navarro, A., Gamero, A., Potla, R., Yi, T., Zhu, W., Baker, D.P., Feldman, G. and Larner, A.C. (2004) Cells previously desensitized to type 1 interferons display different mechanisms of activation of stat-dependent gene expression from naive cells. J Biol Chem 279, 3245-53.

[61] Mertens, C. and Darnell, J.E., Jr. (2007) SnapShot: JAK-STAT signaling. Cell 131, 612.

[62] Klampfer, L., Huang, J., Sasazuki, T., Shirasawa, S. and Augenlicht, L. (2003) Inhibition of interferon gamma signaling by the short chain fatty acid butyrate. Mol Cancer Res 1, 855-62.

[63] Göttlicher, M., Minucci, S., Zhu, P., Krämer, O.H., Schimpf, A., Giavara, S., Sleeman, J.P., Lo, C.F., Nervi, C., Pelicci, P.G. and Heinzel, T. (2001) Valproic acid defines a novel class of HDAC inhibitors inducing differentiation of transformed cells. Embo J 20, 6969-6978.

[64] Genin, P., Morin, P. and Civas, A. (2003) Impairment of interferon-induced IRF-7 gene expression due to inhibition of ISGF3 formation by trichostatin A. J Virol 77, 7113-9.

[65] Sakamoto, S., Potla, R. and Larner, A.C. (2004) Histone deacetylase activity is required to recruit RNA polymerase II to the promoters of selected interferonstimulated early response genes. J Biol Chem 279, 40362-7.

[66] Klampfer, L., Huang, J., Swaby, L.A. and Augenlicht, L. (2004) Requirement of histone deacetylase activity for signaling by STAT1. J Biol Chem 279, 30358-68.

[67] Vlasáková, J., Nováková, Z., Rossmeislová, L., Kahle, M., Hozák, P. and Hodny, Z. (2007) Histone deacetylase inhibitors suppress IFNalpha-induced up-regulation of promyelocytic leukemia protein. Blood 109, 1373-80.

[68] Hayashi, T., Ishida, Y., Kimura, A., Iwakura, Y., Mukaida, N. and Kondo, T. (2007) IFN-gamma protects cerulein-induced acute pancreatitis by repressing NF-kappa B activation. J Immunol 178, 7385-94.

[69] Guo, L., Guo, H., Gao, C., Mi, Z., Russell, W.B. and Kuo, P.C. (2007) Stat1 acetylation inhibits inducible nitric oxide synthase expression in interferon-gammatreated RAW264.7 murine macrophages. Surgery 142, 156-62.

[70] Shchors, K., Shchors, E., Rostker, F., Lawlor, E.R., Brown-Swigart, L. and Evan, G.I. (2006) The Myc-dependent angiogenic switch in tumors is mediated by interleukin 1beta. Genes Dev 20, 2527-38.

[71] Guerra, C., Schuhmacher, A.J., Canamero, M., Grippo, P.J., Verdaguer, L., PerezGallego, L., Dubus, P., Sandgren, E.P. and Barbacid, M. (2007) Chronic pancreatitis is essential for induction of pancreatic ductal adenocarcinoma by K-Ras oncogenes in adult mice. Cancer Cell 11, 291-302.

[72] Missiaglia, E., Blaveri, E., Terris, B., Wang, Y.H., Costello, E., Neoptolemos, J.P., Crnogorac-Jurcevic, T. and Lemoine, N.R. (2004) Analysis of gene expression in cancer cell lines identifies candidate markers for pancreatic tumorigenesis and metastasis. Int J Cancer 112, 100-12. 
[73] Xi, S., Dyer, K.F., Kimak, M., Zhang, Q., Gooding, W.E., Chaillet, J.R., Chai, R.L., Ferrell, R.E., Zamboni, B., Hunt, J. and Grandis, J.R. (2006) Decreased STAT1 expression by promoter methylation in squamous cell carcinogenesis. J Natl Cancer Inst 98, 181-9.

[74] Mantovani, A., Allavena, P., Sica, A. and Balkwill, F. (2008) Cancer-related inflammation. Nature 454, 436-44.

[75] Krämer, O.H., Knauer, S.K., Greiner, G., Jandt, E., Reichardt, S., Gührs, K.H., Stauber, R.H., Böhmer, F.D. and Heinzel, T. (2009) A phosphorylation-acetylation switch regulates STAT1 signaling. Genes Dev 23, 223-35.

[76] Mowen, K.A., Tang, J., Zhu, W., Schurter, B.T., Shuai, K., Herschman, H.R. and David, M. (2001) Arginine methylation of STAT1 modulates IFNalpha/beta-induced transcription. Cell 104, 731-41.

[77] Komyod, W., Bauer, U.M., Heinrich, P.C., Haan, S. and Behrmann, I. (2005) Are STATS arginine-methylated? J Biol Chem 280, 21700-5.

[78] Meissner, T., Krause, E., Lodige, I. and Vinkemeier, U. (2004) Arginine methylation of STAT1: a reassessment. Cell 119, 587-9; discussion 589-590.

[79] Rogers, R.S., Horvath, C.M. and Matunis, M.J. (2003) SUMO modification of STAT1 and its role in PIAS-mediated inhibition of gene activation. J Biol Chem 278, 30091-7.

[80] Song, L., Bhattacharya, S., Yunus, A.A., Lima, C.D. and Schindler, C. (2006) Stat1 and SUMO modification. Blood 108, 3237-44.

[81] Ungureanu, D., Vanhatupa, S., Gronholm, J., Palvimo, J.J. and Silvennoinen, O. (2005) SUMO-1 conjugation selectively modulates STAT1-mediated gene responses. Blood 106, 224-6.

[82] Ungureanu, D., Vanhatupa, S., Kotaja, N., Yang, J., Aittomaki, S., Janne, O.A., Palvimo, J.J. and Silvennoinen, O. (2003) PIAS proteins promote SUMO-1 conjugation to STAT1. Blood 102, 3311-3.

[83] Jakobs, A., Koehnke, J., Himstedt, F., Funk, M., Korn, B., Gaestel, M. and Niedenthal, R. (2007) Ubc9 fusion-directed SUMOylation (UFDS): a method to analyze function of protein SUMOylation. Nat Methods 4, 245-50.

[84] Zimnik, S., Gaestel, M. and Niedenthal, R. (2009) Mutually exclusive STAT1 modifications identified by Ubc9/substrate dimerization-dependent SUMOylation. Nucleic Acids Res 37, e30.

[85] Knobeloch, K.P., Utermohlen, O., Kisser, A., Prinz, M. and Horak, I. (2005) Reexamination of the role of ubiquitin-like modifier ISG15 in the phenotype of UBP43-deficient mice. Mol Cell Biol 25, 11030-4.

[86] Malakhova, O.A., Yan, M., Malakhov, M.P., Yuan, Y., Ritchie, K.J., Kim, K.I., Peterson, L.F., Shuai, K. and Zhang, D.E. (2003) Protein ISGylation modulates the JAK-STAT signaling pathway. Genes Dev 17, 455-60.

[87] Osiak, A., Utermohlen, O., Niendorf, S., Horak, I. and Knobeloch, K.P. (2005) ISG15, an interferon-stimulated ubiquitin-like protein, is not essential for STAT1 signaling and responses against vesicular stomatitis and lymphocytic choriomeningitis virus. Mol Cell Biol 25, 6338-45.

[88] Kim, T.K. and Maniatis, T. (1996) Regulation of interferon-gamma-activated STAT1 by the ubiquitin-proteasome pathway. Science 273, 1717-9.

[89] Blesofsky, W.A., Mowen, K., Arduini, R.M., Baker, D.P., Murphy, M.A., Bowtell, D.D. and David, M. (2001) Regulation of STAT protein synthesis by c-Cbl. Oncogene 20, 7326-33.

[90] Tanaka, T., Soriano, M.A. and Grusby, M.J. (2005) SLIM is a nuclear ubiquitin E3 ligase that negatively regulates STAT signaling. Immunity 22, 729-36. 
[91] Tam, N.W., Ishii, T., Li, S., Wong, A.H., Cuddihy, A.R. and Koromilas, A.E. (1999) Upregulation of STAT1 protein in cells lacking or expressing mutants of the doublestranded RNA-dependent protein kinase PKR. Eur J Biochem 262, 149-54.

[92] Yoshida, K., Okamura, H., Amorim, B.R., Hinode, D., Yoshida, H. and Haneji, T. (2009) PKR-mediated degradation of STAT1 regulates osteoblast differentiation. Exp Cell Res 315, 2105-14.

[93] Gao, C., Mi, Z., Guo, H. and Kuo, P.C. (2007) Osteopontin regulates ubiquitindependent degradation of Stat 1 in murine mammary epithelial tumor cells. Neoplasia 9, 699-706.

[94] He, F., Ge, W., Martinowich, K., Becker-Catania, S., Coskun, V., Zhu, W., Wu, H., Castro, D., Guillemot, F., Fan, G., de Vellis, J. and Sun, Y.E. (2005) A positive autoregulatory loop of Jak-STAT signaling controls the onset of astrogliogenesis. Nat Neurosci 8, 616-25.

[95] Wong, L.H., Sim, H., Chatterjee-Kishore, M., Hatzinisiriou, I., Devenish, R.J., Stark, G. and Ralph, S.J. (2002) Isolation and characterization of a human STAT1 gene regulatory element. Inducibility by interferon (IFN) types I and II and role of IFN regulatory factor-1. J Biol Chem 277, 19408-17.

[96] Hay, R.T. (2005) SUMO: a history of modification. Mol Cell 18, 1-12.

[97] Meulmeester, E. and Melchior, F. (2008) Cell biology: SUMO. Nature 452, 709-11.

[98] Shankaranarayanan, P., Chaitidis, P., Kuhn, H. and Nigam, S. (2001) Acetylation by histone acetyltransferase CREB-binding protein/p300 of STAT6 is required for transcriptional activation of the 15-lipoxygenase-1 gene. J Biol Chem 276, 42753-60.

[99] Rascle, A., Johnston, J.A. and Amati, B. (2003) Deacetylase activity is required for recruitment of the basal transcription machinery and transactivation by STAT5. Mol Cell Biol 23, 4162-73.

[100] Ray, S., Lee, C., Hou, T., Boldogh, I. and Brasier, A.R. (2008) Requirement of histone deacetylase1 (HDAC1) in signal transducer and activator of transcription 3 (STAT3) nucleocytoplasmic distribution. Nucleic Acids Res 36, 4510-20.

[101] Wang, R., Cherukuri, P. and Luo, J. (2005) Activation of Stat3 sequence-specific DNA binding and transcription by $\mathrm{p} 300 / \mathrm{CREB}-$ binding protein-mediated acetylation. J Biol Chem 280, 11528-34.

[102] Yuan, Z.L., Guan, Y.J., Chatterjee, D. and Chin, Y.E. (2005) Stat3 dimerization regulated by reversible acetylation of a single lysine residue. Science 307, 269-73.

[103] Ray, S., Boldogh, I. and Brasier, A.R. (2005) STAT3 NH2-terminal acetylation is activated by the hepatic acute-phase response and required for IL-6 induction of angiotensinogen. Gastroenterology 129, 1616-32.

[104] Hou, T., Ray, S., Lee, C. and Brasier, A.R. (2008) The STAT3 NH2-terminal domain stabilizes enhanceosome assembly by interacting with the p300 bromodomain. J Biol Chem 283, 30725-34.

[105] O'Shea, J.J., Kanno, Y., Chen, X. and Levy, D.E. (2005) Cell signaling. Stat acetylation--a key facet of cytokine signaling? Science 307, 217-8.

[106] Schreiber, S.L. and Bernstein, B.E. (2002) Signaling network model of chromatin. Cell 111, 771-8.

[107] Yang, X.J. (2004) Lysine acetylation and the bromodomain: a new partnership for signaling. Bioessays 26, 1076-87.

[108] Hung, W.C. and Chuang, L.Y. (1999) Sodium butyrate enhances STAT 1 expression in PLC/PRF/5 hepatoma cells and augments their responsiveness to interferon-alpha. Br J Cancer 80, 705-10.

[109] Buchwald, M., Krämer, O.H. and Heinzel, T. (2009) HDACi - Targets beyond chromatin. Cancer Lett. 
[110] Wojciak, J.M., Martinez-Yamout, M.A., Dyson, H.J. and Wright, P.E. (2009) Structural basis for recruitment of CBP/p300 coactivators by STAT1 and STAT2 transactivation domains. Embo J 28, 948-58.

[111] Melén, K., Kinnunen, L. and Julkunen, I. (2001) Arginine/lysine-rich structural element is involved in interferon-induced nuclear import of STATs. J Biol Chem 276, 16447-55.

[112] Perotti, C., Liu, R., Parusel, C.T., Bocher, N., Schultz, J., Bork, P., Pfitzner, E., Groner, B. and Shemanko, C.S. (2008) Heat shock protein-90-alpha, a prolactinSTAT5 target gene identified in breast cancer cells, is involved in apoptosis regulation. Breast Cancer Res 10, R94.

[113] Xu, R., Nelson, C.M., Muschler, J.L., Veiseh, M., Vonderhaar, B.K. and Bissell, M.J. (2009) Sustained activation of STAT5 is essential for chromatin remodeling and maintenance of mammary-specific function. J Cell Biol 184, 57-66.

[114] Naugler, W.E., Sakurai, T., Kim, S., Maeda, S., Kim, K., Elsharkawy, A.M. and Karin, M. (2007) Gender disparity in liver cancer due to sex differences in MyD88dependent IL-6 production. Science 317, 121-4.

[115] Borrello, M.G., Alberti, L., Fischer, A., Degl'innocenti, D., Ferrario, C., Gariboldi, M., Marchesi, F., Allavena, P., Greco, A., Collini, P., Pilotti, S., Cassinelli, G., Bressan, P., Fugazzola, L., Mantovani, A. and Pierotti, M.A. (2005) Induction of a proinflammatory program in normal human thyrocytes by the RET/PTC1 oncogene. Proc Natl Acad Sci U S A 102, 14825-30.

[116] Blanchard, F. and Chipoy, C. (2005) Histone deacetylase inhibitors: new drugs for the treatment of inflammatory diseases? Drug Discov Today 10, 197-204.

[117] Marx, J. (2004) Cancer research. Inflammation and cancer: the link grows stronger. Science 306, 966-8.

[118] Pikarsky, E., Porat, R.M., Stein, I., Abramovitch, R., Amit, S., Kasem, S., GutkovichPyest, E., Urieli-Shoval, S., Galun, E. and Ben-Neriah, Y. (2004) NF-kappaB functions as a tumour promoter in inflammation-associated cancer. Nature 431, 461-6.

[119] Métivier, R., Penot, G., Carmouche, R.P., Hubner, M.R., Reid, G., Denger, S., Manu, D., Brand, H., Kos, M., Benes, V. and Gannon, F. (2004) Transcriptional complexes engaged by apo-estrogen receptor-alpha isoforms have divergent outcomes. Embo J 23, 3653-66. 
Figure 1

Cytokine Estrogen EGF Growth hormone

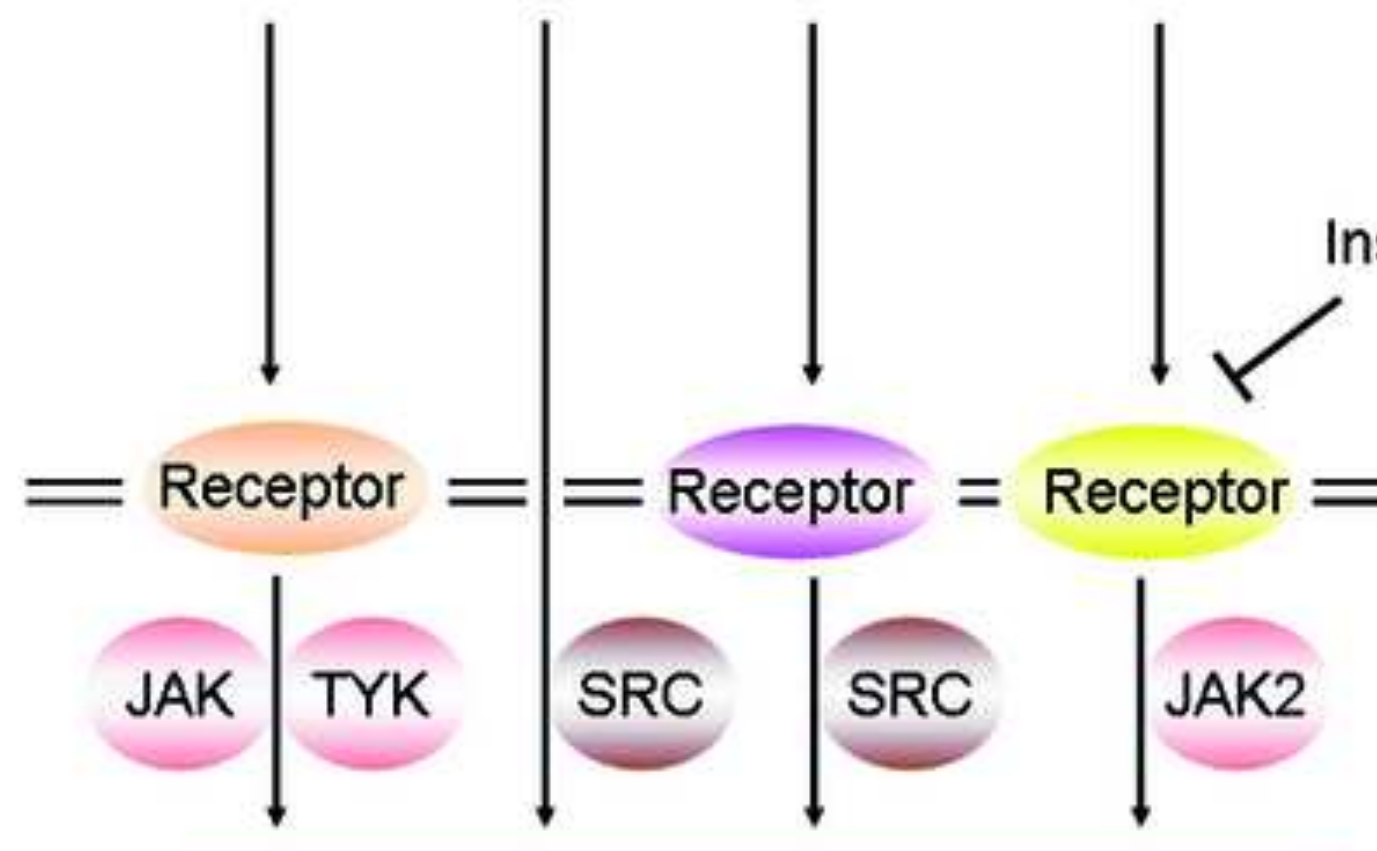

Cytosol

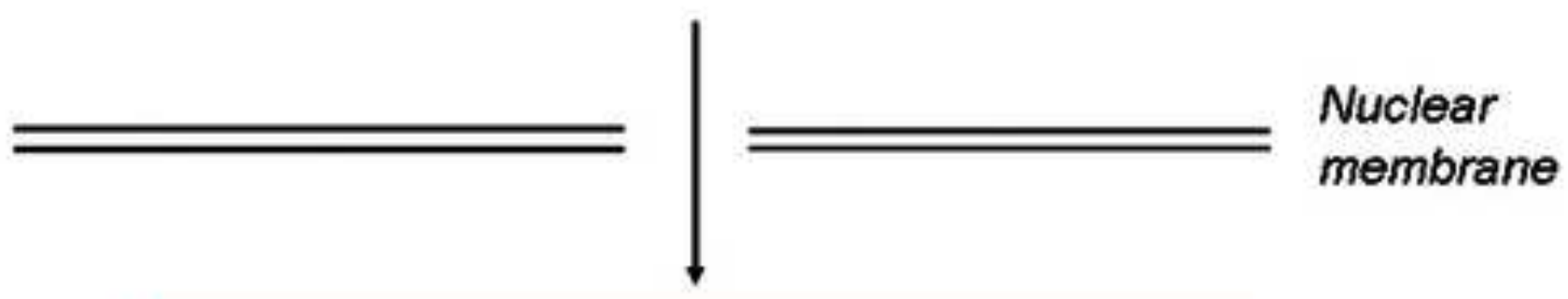

Nucleus 
Figure 2

STAT1

\begin{tabular}{|c|c|c|c|}
\hline \multicolumn{4}{|c|}{ Domains } \\
\hline NTD & CC $\begin{array}{c}\text { DBD LD } \\
\text { Amino acids }\end{array}$ & $\mathrm{SH} 2$ & TAD \\
\hline $1-136$ & $316-488$ & $576-683$ & 739 \\
\hline & & & \\
\hline & $\begin{array}{l}\text { K410·ac } \\
\text { K413.ac }\end{array}$ & & $\begin{array}{l}\text { Y701 } \\
\text { S727 }\end{array}$ \\
\hline
\end{tabular}

STAT3

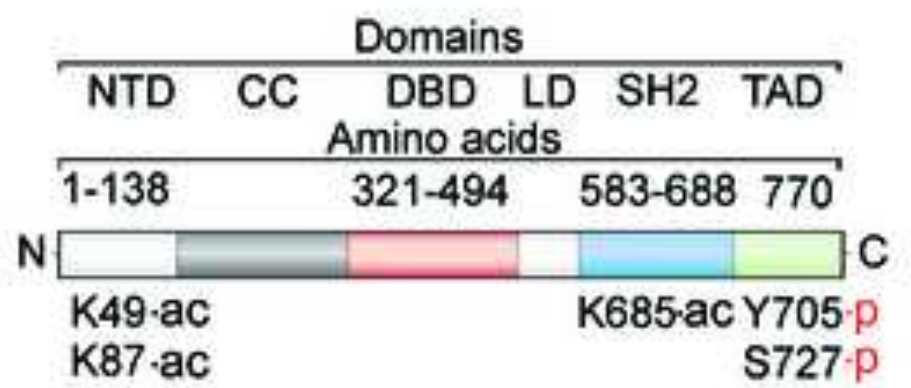

Lysine<smiles>NCCCC[C@H](N)C(=O)O</smiles>

Acetyl-Lysine<smiles>CC(=O)NCCCC[C@H](N)C(=O)O</smiles>

Glutamine<smiles>NC(=O)CCC(N)C(=O)O</smiles>

Arginine<smiles>N=C(N)NCCC[C@H](N)C(=O)O</smiles> 
Figure 3

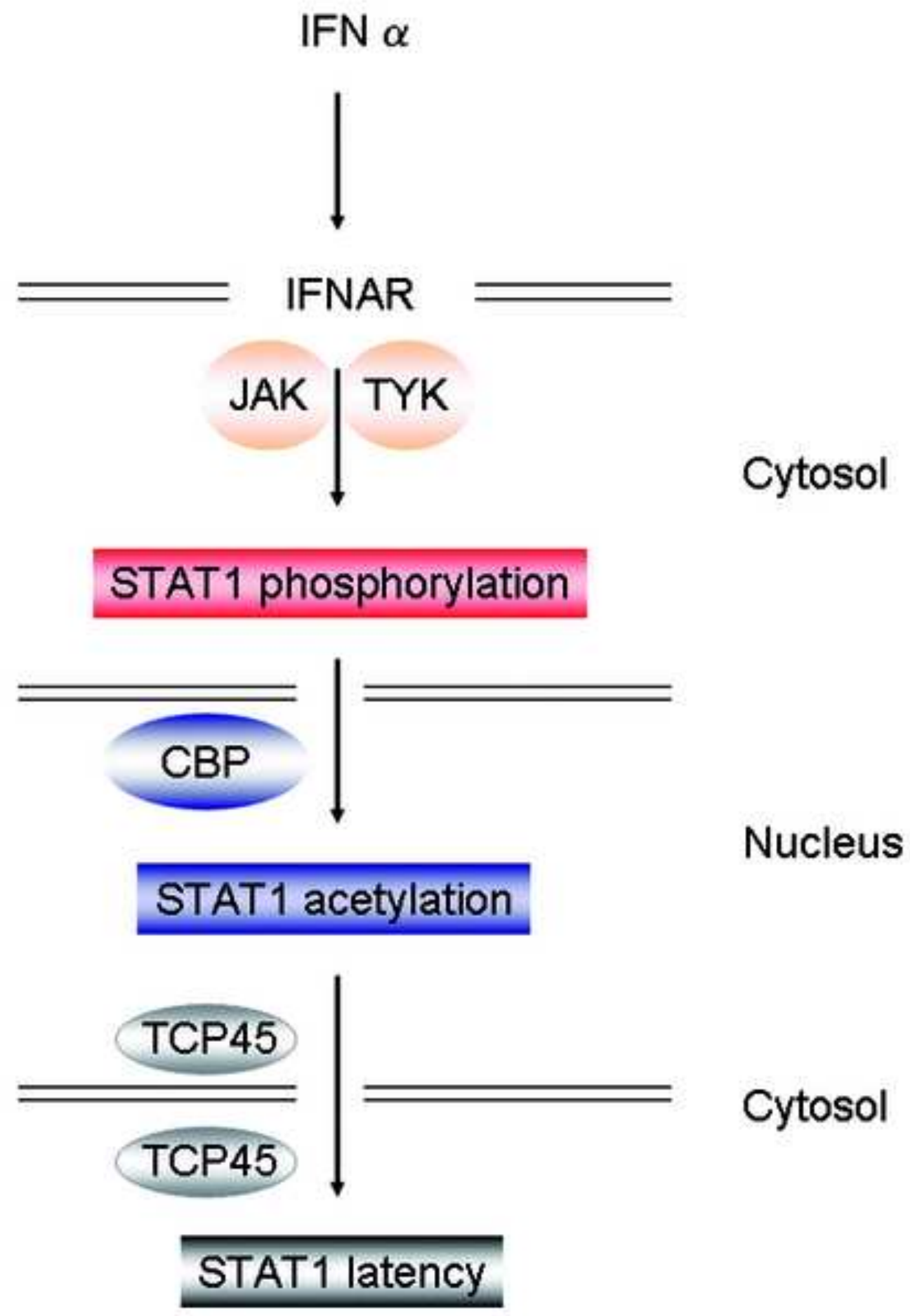




\section{Figure 4 4}
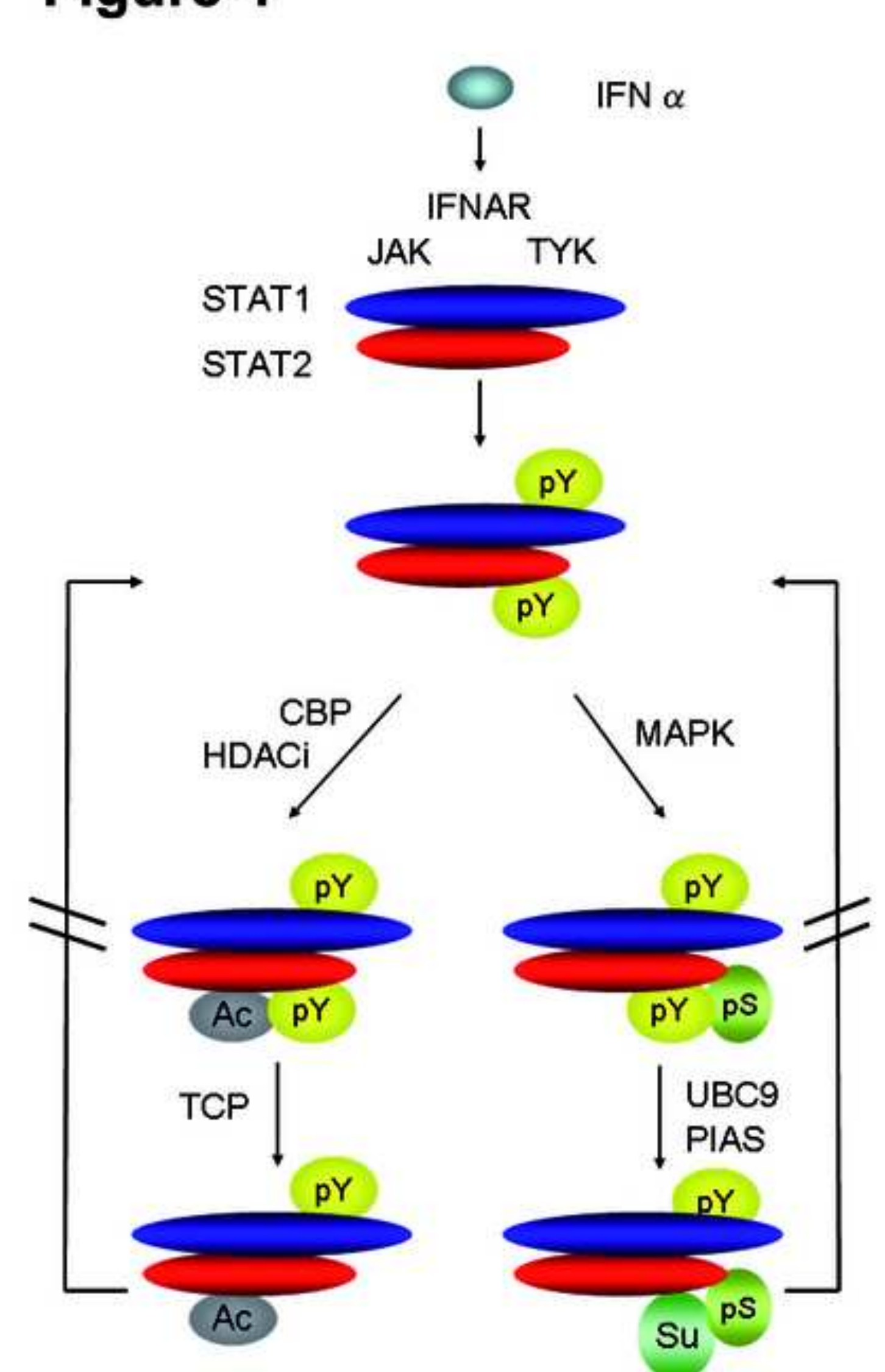

FNAR

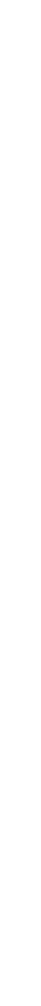


Figure 5

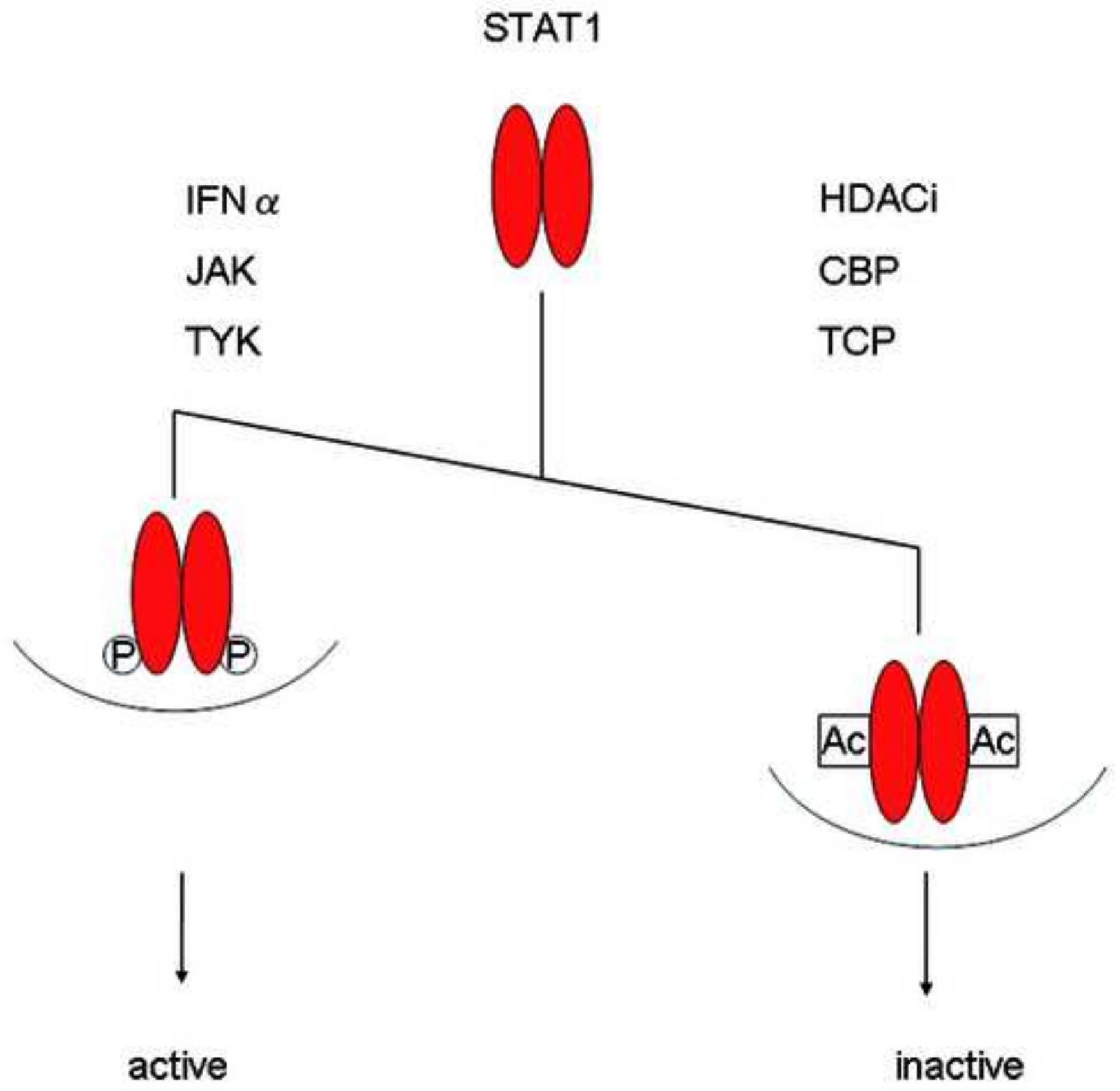

Page 25 of 26 


\section{Figure 6}

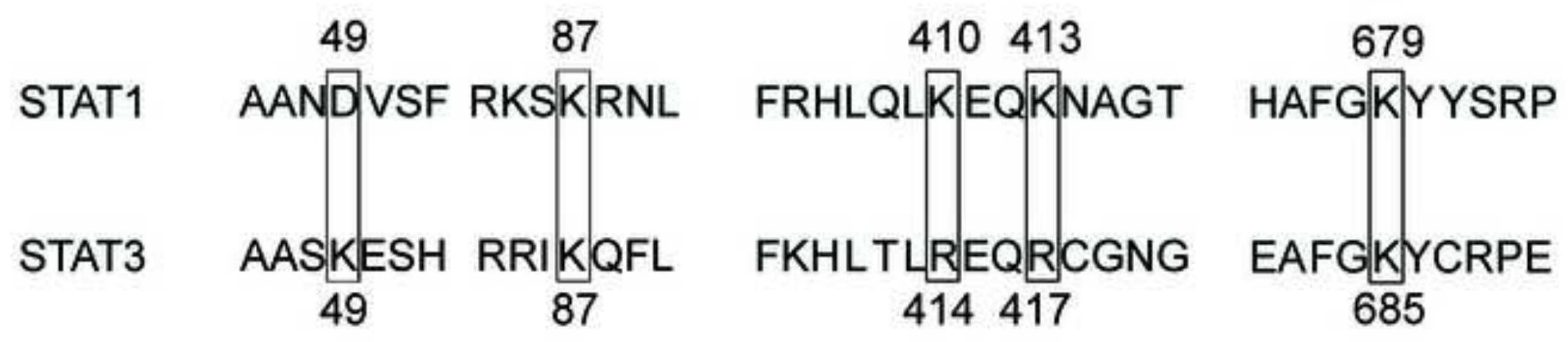

